\title{
Association between MDM2-SNP309 and p53R72P polymorphisms and the risk of bladder cancer in the Mongolian population
}

\author{
SHIIREVNYAMBA AVIRMED ${ }^{1}$, BO-SHEN WANG ${ }^{2}$, BAASANSUREN SELENGE $^{1}$, \\ AMARSAIKHAN SANJAAJAMTS ${ }^{1}$, BATMUNKH GANBAT ${ }^{1}$, ULZIISAIKHAN ERDENEBILEG ${ }^{1}$, \\ MYAGMARSUREN PUREVSUREN ${ }^{1,3}$, SARANTSETSEG JIGJIDSUREN ${ }^{4}$, \\ MUNKHBAT BATMUNKH ${ }^{5}$ and YI-JANG LEE ${ }^{2,6}$
}

\begin{abstract}
${ }^{1}$ Division of Urology, Department of Surgery, School of Medicine, Mongolian National University of Medical Sciences, Ulaanbaatar 14210, Mongolia; ${ }^{2}$ Department of Biomedical Imaging and Radiological Sciences, School of Biomedical Engineering, National Yang-Ming University, Taipei 112, Taiwan; Departments of ${ }^{3}$ Urology and ${ }^{4}$ Clinical Laboratory, First Central Hospital of Mongolia, Ulaanbaatar 210648, Mongolia; ${ }^{5}$ Science Technology Center, Mongolian National University of Medical Sciences, Ulaanbaatar 14210, Mongolia; ${ }^{6}$ Biophotonics and Molecular Imaging

Research Center (BMIRC), National Yang-Ming University, Taipei 112, Taiwan
\end{abstract}

Received June 9, 2016; Accepted April 13, 2017

DOI: $10.3892 / \mathrm{mco} .2017 .1317$

\begin{abstract}
The current study aims to investigate whether MDM2-SNP309 and p53R72P polymorphisms were associated with the risk of bladder cancer in Mongolian populations. These polymorphisms were evaluated in 79 controls and 63 bladder cancer cases using a PCR-restriction fragment length polymorphism assay, followed by analysis using multivariate logistic regression model and the Kaplan-Meier model to determine the odds ratio (OR) and age at onset of bladder cancer, respectively. The results revealed that the homozygous $(\mathrm{G} / \mathrm{G})$ genotype of MDM2-SNP309 increased the risk of bladder cancer compared to the wild-type $(\mathrm{T} / \mathrm{T})$ genotype [OR=1.629; $95 \%$ confidence interval $(\mathrm{CI})=0.622-4.266]$ among Mongolians. On the other hand, the homozygous $(\mathrm{P} / \mathrm{P})$ genotype of $\mathrm{p} 53 \mathrm{R} 72 \mathrm{P}$ tended to protect the population from bladder cancer compared with the wild-type $(\mathrm{R} / \mathrm{R})$ genotype $(\mathrm{OR}=0.445 ; 95 \% \mathrm{CI}=0.1727-2.147)$. It also showed that G/G genotype of MDM2-SNP309 increased the risk of bladder cancer when combined with the $\mathrm{R} / \mathrm{R}$ genotype of p53R72P (OR=3.355; 95\% CI=0.3914-28.766).
\end{abstract}

Correspondence to: Dr Shiirevnyamba Avirmed, Division of Urology, Department of Surgery, School of Medicine, Mongolian National University of Medical Sciences, 3 Zorig Street, Ulaanbaatar 14210, Mongolia

E-mail: shiirevnyamba@mnums.edu.mn

Dr Yi-Jang Lee, Department of Biomedical Imaging and Radiological Sciences, National Yang-Ming University, 155, Sec. 2, Linong St. Beitou District, Taipei 112, Taiwan

E-mail: yjlee2@ym.edu.tw

Key words: bladder cancer, Mongolian patients, MDM2-SNP309, p53R72P, risk association
Stratification by smoking and history of chronic urinary tract diseases tended towards increasing the risk association of the $\mathrm{G} / \mathrm{G}(\mathrm{OR}=2.3704 ; 95 \% \mathrm{CI}=0.4308-3.044)$ and $\mathrm{T} / \mathrm{G}$ genotypes $(\mathrm{OR}=5 ; 95 \% \mathrm{CI}=0.8442-30.4088)$ of MDM2-SNP309 with bladder cancer, respectively. The protective role of $\mathrm{P} / \mathrm{P}$ of p53R72P remained following stratification. MDM2-SNP309 and p53R72P were not involved in early age onset of bladder cancer in Mongolian patients. Taken together, MDM2-SNP309 and p53R72P had no significant association with bladder cancer in Mongolian patients. The two SNPs were also not able to predict early age at onset of bladder cancer.

\section{Introduction}

The incidence of bladder cancer is increasing and it is the most common urinary malignant tumor worldwide (1). It is the second most common urological malignancy in the Mongolian population (2). A histological study examining 108 Mongolian patients with urinary bladder cancer revealed that 2, 12 and $86 \%$ of the patients were diagnosed with papilloma, papillary urothelial neoplasm of low malignant potential and transitional cell carcinoma, respectively (3). Various environmental and genetic risk factors such as smoking, occupational exposure to aromatic amines, male sex, older age and bladder infections are associated with bladder cancer development $(4,5)$. Furthermore, certain genetic alterations in bladder cancer including p53 tumor suppressor gene and its regulating gene, human homolog of murine double minute (MDM2) are considered to be associated with cancer susceptibility (6). Whether genetic polymorphisms in these genes also has a role in the risk of bladder cancer remains to be addressed.

P53 genomic sequence mutation is typically concentrated in the region of exons 4-9 when it is detected in human cancer $(7,8)$. P53 codon $72 \mathrm{G}$ to $\mathrm{C}$ polymorphism (p53R72P) 
is found in exon 4 and is a well-known single nucleotide polymorphism (SNP) that alters arginine to proline (9). The two forms are morphologically wild-type, but such variants of p53 may target varying transcriptional elements (10). Previous meta-analyses have reported that $\mathrm{p} 53 \mathrm{R} 72 \mathrm{P}$ is associated with the risk of bladder cancer in Asian but not Caucasian patients $(11,12)$. However, these studies did not include Mongolian populations, and the risk association in this population remains to be investigated.

A functional SNP was also identified at position 309 of the first intron at the $\mathrm{P} 2$ promoter region of human $M D M 2$, termed MDM2-SNP309 (rs2279744) (13). The conversion from the $\mathrm{T}$ to $\mathrm{G}$ allele in this SNP increases the binding of the general transcription activator $\mathrm{Sp} 1$ to the promoter and enhances the expression of the MDM2 gene, which in turn promotes the degradation of p53 and leads to a higher risk of carcinogenesis $(14,15)$. For bladder cancer, the homozygous variant of MDM2-SNP309 is not associated with overall risk of bladder cancer but may influence the invasive growth of bladder cancer in German populations (16). A study examining Turkish populations reported that the MDM2 T309G polymorphism is a potential genetic susceptibility factor for bladder cancer (17). Another previous study, conducted in the USA, revealed that SNP309 is associated with earlier onset of superficial tumors, poorer clinical outcomes and TP53 mutation status in invasive bladder cancer (18). A study conducted in Japan revealed no significant associations between each genotype of the MDM2 SNP309 and p53 Arg72Pro polymorphisms and bladder cancer risk, but the polymorphisms may influence the clinical outcome of bladder cancer (19). However, investigations have been inconsistent, and the hypothesized association remains controversial. These inconclusive and conflicting results may be associated with the different patient subgroups and ethnicities studied.

In the present study, the risk association between $\mathrm{p} 53 \mathrm{R} 72 \mathrm{P}$ and MDM2-SNP309 and bladder cancer in Mongolian patients was analyzed using the logistic regression method. The age onset of patients with bladder cancer was also compared among the different genotypes of these two genetic polymorphisms.

\section{Patients and methods}

Patients. A total of 79 cancer-free healthy controls and 63 patients with histologically confirmed bladder cancer who were diagnosed in the First Central Hospital of Mongolia (Ulaanbaatar, Mongolia) were enrolled in the study. Patients with bladder cancer were not selected according to their age, sex or tumor stage. Age- and gender-matched controls were enrolled in this study. All patients provided informed consent and completed structured questionnaires. The questionnaire included information about risk factors for bladder cancer such as age, sex, body mass index, socioeconomic status, occupational exposure, dietary factors, smoking, alcohol drinking, drug usage, history of chronic urinary tract diseases and exercising. This study was approved by the Ethics Committee of the Ministry of Health of Mongolia (No. 4), and the institutional review board of National Yang-Ming University, Taiwan (YM102005). The approval documents will be provided upon request. All participants were native Mongolians and aged $>18$ years.
Genotyping. In total, $3 \mathrm{ml}$ whole blood was collected from cancer-free healthy controls and patients with bladder cancer for genotyping of p53R72P and MDM2-SNP309 after written informed consent was obtained. The procedures of MDM2-SNP309 and p53R72P genotyping was performed as described previously (18). In brief, DNA was extracted from $200 \mu \mathrm{l}$ of blood using the Qiagen mini blood DNA extraction kit (Qiagen, Inc., Valencia, CA, USA) and MDM2 SNP309 was amplified by polymerase chain reaction (PCR) using the following primers: Forward, 5'-CGGGAGTTCAGGGTAAAG GT-3'; and reverse, 5'-AGCAAGTCGGTGCTTACCTG-3'. The PCR reactions consisted of $100 \mathrm{ng}$ of genomic DNA, $0.2 \mu \mathrm{M}$ primer, $200 \mu \mathrm{M}$ dNTP, $1.5 \mathrm{mM} \mathrm{MgCl}$, $20 \mathrm{mM}$ Tris- $\mathrm{HCl}(\mathrm{pH}$ 8.4), $50 \mathrm{mM} \mathrm{KCl}$ and $1 \mathrm{U}$ of Platinum Taq DNA polymerase (Invitrogen; Thermo Fisher Scientific, Waltham, MA, USA). The thermal cycling conditions were $1 \mathrm{~min}$ at $94^{\circ} \mathrm{C} ; 40$ cycles of denaturing at $94^{\circ} \mathrm{C}$, annealing at $58^{\circ} \mathrm{C}$, and elongation at $72^{\circ} \mathrm{C}$ for $30 \mathrm{sec}$ each, followed by one cycle at $72^{\circ} \mathrm{C}$ for $10 \mathrm{~min}$. For restriction fragment length polymorphism analysis, 10-20 $\mu \mathrm{l}$ of the amplified 352-bp fragment was digested with $1 \mathrm{U}$ of MspA1I restriction enzyme (New England Biolabs, Inc., Ipswich, MA, USA) at $37^{\circ} \mathrm{C}$ in a water bath for $30 \mathrm{~min}$ to $1 \mathrm{~h}$. The $\mathrm{T} / \mathrm{T}, \mathrm{T} / \mathrm{G}$ and $\mathrm{G} / \mathrm{G}$ genotypes were distinguished by bands with lengths of 233 and 88; 233, 187 and 88 bp; and 187 and 88 bp, respectively, following electrophoresis. The same procedure was used for genotyping p53 codon 72 polymorphism (20). The primers were as follows: Forward, 5'-TTT CACCCATCTACAGTCCC-3'; reverse, 5'-CGGTGTAGG AGCTGCTG-3'. The length of the PCR product was $166 \mathrm{bp}$, then it was digested with BstU1 at $60^{\circ} \mathrm{C}$ for $1 \mathrm{~h}$. The digestion of the $\mathrm{P} / \mathrm{P}$ variant yielded a $166-\mathrm{bp}$ band, the $\mathrm{R} / \mathrm{R}$ variant yielded 135- and 31-bp bands and the $\mathrm{P} / \mathrm{R}$ heterozygous variant yielded 166, 135 and 31 bp bands.

Statistical analysis. The genotype and allele frequency were tested for Hardy-Weinberg equilibrium. Discrepancies between controls and cases were determined using $2 \times 2 \chi^{2}$ tables or two-sample t-tests. Multivariate logistical regression analysis with adjustment or stratification was used to determine odds ratios (OR) and 95\% confidence intervals (CI) for evaluating the risk association of MDM2-SNP309 and p53R72P with the incidence of bladder cancer. The Kaplan-Meier method with the log-rank test was used to analyze the age at diagnosis of these genotypes. Statistical evaluation was performed using the demo version of Medcalc 9.5.1.0 software (MedCalc Software, Mariakerke, Belgium). $\mathrm{P} \leq 0.05$ was considered to indicate a statistically significant difference.

\section{Results}

Characteristics of bladder cancer cases and controls. One hundred and twenty-nine cancer-free controls and 141 patients with bladder cancer were initially enrolled in the present study. However, characteristics of patients and controls were only recorded in 79 controls and 63 patients with bladder cancer, as they had provided the full information requested in the questionnaires. The demography of 142 Mongolian volunteers awas summarized in Table I. There were 3.5 times more male than female patients. Smoking, alcohol drinking and exercise, as well as the history of chronic urinary tract disease were 
Table I. The demography of patients with bladder cancer and cancer-free controls.

\begin{tabular}{|c|c|c|c|}
\hline Characteristics & Controls $(\%)(\mathrm{n}=79)$ & Cases $(\%)(n=63)$ & P-value ${ }^{a}$ \\
\hline Age, years & & & 0.2263 \\
\hline Mean & 58.3 & 55.6 & \\
\hline $\mathrm{SD}$ & 13.5 & 12.7 & \\
\hline Sex & & & 0.9551 \\
\hline Male & $60(76)$ & $49(78)$ & \\
\hline Female & $19(24)$ & $14(22)$ & \\
\hline Smoking & & & $<0.0001$ \\
\hline Yes & $19(24)$ & $45(73)$ & \\
\hline No & $60(76)$ & $18(27)$ & \\
\hline Alcohol drinking & & & 0.045 \\
\hline Yes & $19(24)$ & $26(41)$ & \\
\hline No & $60(76)$ & $37(59)$ & \\
\hline $\mathrm{HCI}$ & & & 0.1697 \\
\hline Yes & $79(100)$ & $60(95)$ & \\
\hline No & $0(0)$ & $3(5)$ & \\
\hline Coffee & & & 0.2292 \\
\hline Yes & $25(32)$ & $27(43)$ & \\
\hline No & $54(68)$ & $36(57)$ & \\
\hline CVD & & & 0.8225 \\
\hline Yes & $14(18)$ & $13(21)$ & \\
\hline No & $65(82)$ & $50(79)$ & \\
\hline History of CUTD & & & $<0.0001$ \\
\hline Yes & $10(13)$ & $34(54)$ & \\
\hline No & $69(87)$ & $29(46)$ & \\
\hline Exercise & & & 0.0175 \\
\hline Yes & $9(11)$ & $18(29)$ & \\
\hline No & $70(89)$ & $45(71)$ & \\
\hline
\end{tabular}

The total number of donors with complete information is 142, while that with random missing information is 270 (control, 129; cases, 141). ${ }^{a}$ For statistical analysis, age was determined by two-sample t-tests, and all other parameters were determined by $\chi^{2}$ tests. HCI, high calorie intake; CVD, cardiovascular disease; CUTD, chronic urinary tract disease; SD, standard deviation.

significantly different between cases and controls $(\mathrm{P}<0.05)$. Thus, these characteristics were considered confounders that were adjusted for in the odds ratio in the multivariate logistic regression analysis.

Allelic frequency analysis of MDM2-SNP309 and p53R72P. The allelic frequencies of MDM2-SNP309 and p53R72P were next analyzed in these 142 Mongolians. For MDM2-SNP309, the number and percentage of wild-type (T/T), heterozygote $(\mathrm{T} / \mathrm{G})$ and homozygote $(\mathrm{G} / \mathrm{G})$ alleles was $18(22.7 \%)$, $44(55.7 \%)$ and $17(21.6 \%)$ in the controls, respectively, whereas for bladder cancer cases, these values were 13 (20.6\%), 30 $(47.6 \%)$ and $20(31.7 \%)$, respectively. The genotype frequency of MDM2-SNP309 in both controls and cases obeyed the Hardy-Weinberg equilibrium. The number and percentage of p53R72P genotypes were wild-type (R/R) 37 (46.8\%), heterozygote (R/P) 23 (29.1\%) and homozygote (P/P) 19 (24.1\%) alleles in controls, whereas in bladder cancer cases the $\mathrm{R} / \mathrm{R}$, $\mathrm{R} / \mathrm{P}$ and $\mathrm{P} / \mathrm{P}$ alleles were 35 (55.6\%), 20 (31.7\%) and 8 (12.7\%), respectively. Unlike MDM2-SNP309, the allelic frequency of p53R72P in controls ( $\mathrm{R}, 61 \%$; P, 39\%) was different from that of bladder cancer cases ( $\mathrm{R}, 71 \%$; P, 29\%). The genotype frequency of p53R72P in bladder cancer cases obeyed the Hardy-Weinberg equilibrium, but not in controls. The analysis of allelic frequencies of MDM2-SNP309 and p53R72P is summarized in Table II.

Association between MDM2-SNP309 and p53R72P and the risk of the bladder cancer. To investigate the association between MDM2-SNP309 and p53R72P polymorphisms and the risk of bladder cancer in Mongolian patients, a multivariate logistic regression model was used to calculate the ORs of heterozygotes and homozygotes relative to the wild-type genotype. For MDM2-SNP309, the crude OR of the homozygous genotype (G/G) was 1.629 (95\% CI=0.622-4.2663) compared with the wild-type genotype (T/T). On the contrary, the OR of the heterozygous genotype $(\mathrm{T} / \mathrm{G})$ was $0.944(95 \%$ $\mathrm{CI}=0.4031-2.2111$ ). The confounders-adjusted $\mathrm{ORs}$ of the $\mathrm{G} / \mathrm{G}$ 


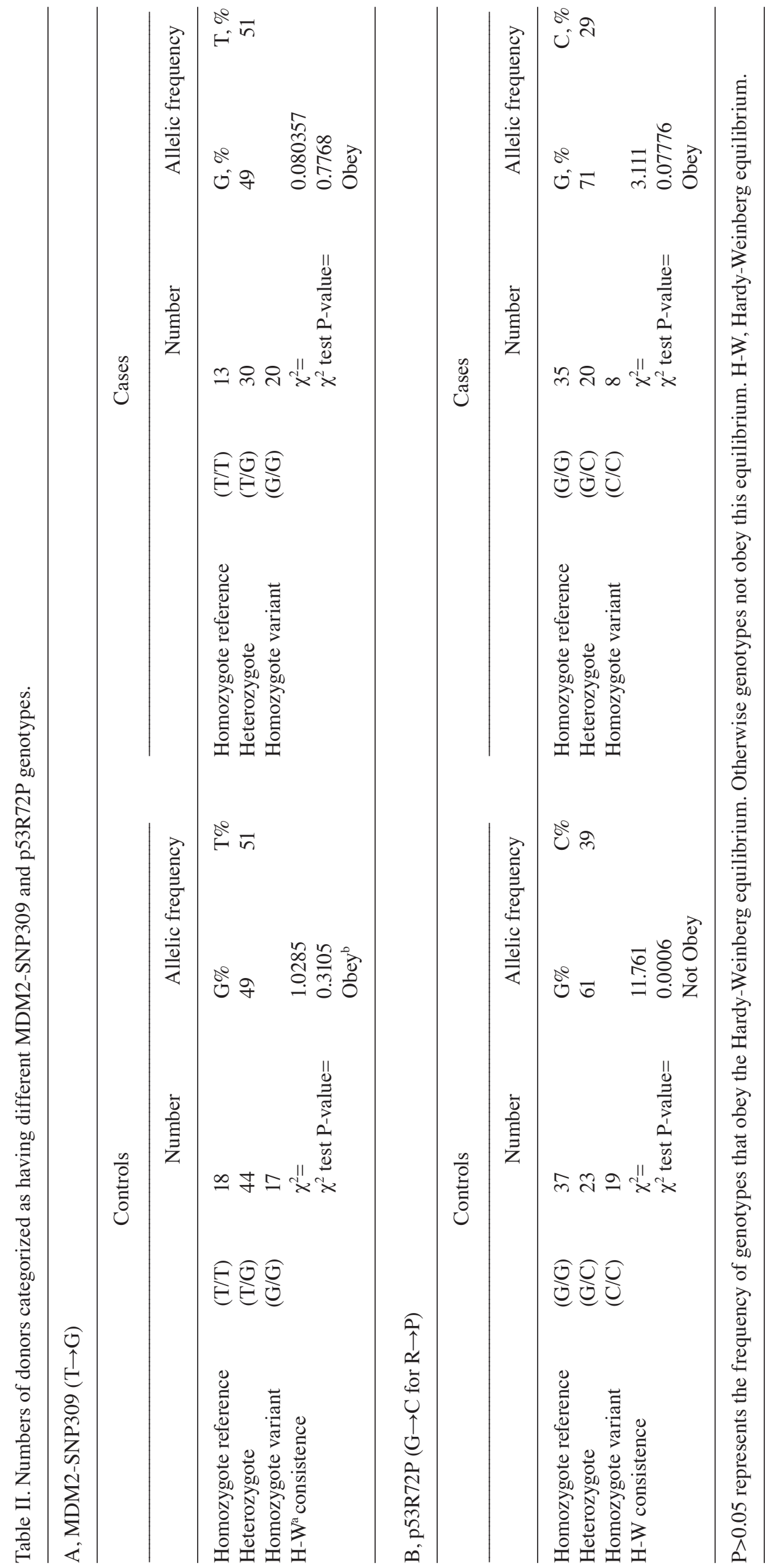


Table III. Risk evaluation of the MDM2 SNP309 and p53R72P genotypes and the development of bladder cancer in the Mongolian population.

\begin{tabular}{|c|c|c|c|c|}
\hline Genotypes & OR $(95 \% \mathrm{CI})^{\mathrm{a}}$ & P-value & OR $(95 \% \mathrm{CI})^{\mathrm{b}}$ & P-value \\
\hline \multicolumn{5}{|c|}{ MDM2-SNP309 } \\
\hline TT & 1 (reference) & & 1 (reference) & \\
\hline $\mathrm{TG}$ & $0.944(0.4031$ to 2.2111$)$ & 0.8945 & $0.993(0.3246$ to 3.0403$)$ & 0.9908 \\
\hline GG & $1.629(0.622$ to 4.2663$)$ & 0.3206 & $1.306(0.3938$ to 4.3304$)$ & 0.6626 \\
\hline $\mathrm{TG}+\mathrm{GG}$ & $1.135(0.5072$ to 2.5396$)$ & 0.7581 & $1.074(0.3869$ to 2.9789$)$ & 0.8915 \\
\hline \multicolumn{5}{|l|}{ p53R72P } \\
\hline $\mathrm{RR}(\mathrm{GG})^{\mathrm{c}}$ & 1 (reference) & & 1 (reference) & \\
\hline $\mathrm{PR}(\mathrm{GC})$ & $0.919(0.4313$ to 1.9593$)$ & 0.8274 & $0.598(0.2128$ to 1.6791$)$ & 0.3288 \\
\hline $\mathrm{PP}(\mathrm{CC})$ & $0.445(0.1727$ to 1.147$)$ & 0.0937 & $0.491(0.1487$ to 1.6199$)$ & 0.3503 \\
\hline $\mathrm{PP}+\mathrm{PR}$ & $0.705(0.3624$ to 1.3704$)$ & 0.3024 & $0.566(0.2409$ to 1.3302$)$ & 0.1918 \\
\hline
\end{tabular}

and $\mathrm{T} / \mathrm{G}$ genotypes were $1.306(95 \% \mathrm{CI}=0.3938-4.2204)$ and 0.993 (95\% CI=0.3246-3.0403), respectively. Notably, the crude OR and adjusted OR for the homozygous genotype of p53R72P were $0.445(95 \% \mathrm{CI}=0.1727-1.147)$ and 0.491 (95\% CI=0.1487-1.6199), respectively. However, the ORs of MDM2-SNP309 and p53R72P were not significant (Table III). Thus, the current analysis showed that the homozygous genotype $(\mathrm{G} / \mathrm{G})$ of MDM2-SNP309 tended to increase the risk of bladder cancer in Mongolian populations, but this effect was not observed for p53R72P.

Risk evaluation of MDM2-SNP309 and p53R72P genotypes and bladder cancer development. MDM2-SNP309 and p53R72P were examined by stratifying according to the following potential confounding factors: Smoking, alcohol drinking and history of chronic urinary tract diseases, as stated in Table I. The G/G genotype of MDM2-SNP309 had a higher risk in the smoking group (OR, 2.3704; 95\% $\mathrm{CI}=0.4308-13.0436)$ than the non-smoker group (OR, 1; 95\% $\mathrm{CI}=0.2077-4.8138)$. Furthermore, the $\mathrm{G} / \mathrm{G}$ and $\mathrm{T} / \mathrm{G}$ genotypes of MDM2-SNP309 were associated with the risk of bladder cancer following stratification by history of chronic urinary tract diseases. For alcohol drinking, the G/G genotype of MDM2-SNP309 had a protective effect on the risk of bladder cancer (OR, 0.6944; 95\% CI=0.1296-3.7203), whereas the $\mathrm{T} / \mathrm{G}$ genotype increased the risk of bladder cancer (OR, 1.5625; 95\% CI, 0.3612-6.7587). The P/R genotype of the p53R72P was also associated with increased risk (OR, 1.875; 95\% $\mathrm{CI}=0.4415-7.9631)$ of bladder cancer following stratification by alcohol drinking, but not the P/P genotype (OR, $0.5 ; 95 \%$ $\mathrm{CI}=0.108-2.3142)$. Although the ORs were altered after stratification, the results of the statistical analysis were not significant (Table IV). Therefore, the adjusted ORs of MDM2-SNP309 and p53R72P genotypes revealed no risk association between these SNPs and bladder cancer in Mongolian patients.

Evaluation of the effect of MDM2-SNP309 on the risk of bladder cancer after stratification by p53R72P. To investigate whether MDM2-SNP309 and p53R72P interact to influence the risk of bladder cancer, the genotypes of p53R72P were stratified by MDM2-SNP309 genotype. Based on this dataset, the results revealed no significant effects regarding the homozygous genotype $(\mathrm{G} / \mathrm{G})$ of MDM2-SNP309 and the risk of bladder cancer in Mongolian patients in the RR group of the p53R72P SNP (OR, 3.3554; 95\% CI=0.3914-28.7657). For heterozygous (R/P) genotypes of p53R72P, both genotypes of MDM2-SNP309 showed no risk association with bladder cancer. All of these results are summarized in Table V.

Comparison of different genotypes of MDM2-SNP309 and p53R72P and the age at diagnosis of bladder cancer. The median age at diagnosis of bladder cancer in Mongolian patients was compared among different genotypes of MDM2-SNP309 and p53R72P. The results were obtained from 84 patients with bladder cancer with registered age at diagnosis. For MDM2-SNP309, the median ages of G/G (60 years) and T/G (59 years) genotypes were older than that of wild-type (T/T) genotype (50.5 years) (Table VI). However, there was no significant difference among these three genotypes of MDM2-SNP309 (Fig. 1A). For p53R72P, the median patients age at diagnosis for the R/P genotype (52 years) was lower than for the homozygous (RR, 58; PP, 61) genotypes (Table VII); however, among the p53R72P genotypes no significant differences were identified (Fig. 1B).

\section{Discussion}

The current study investigated the association between the MDM2 SNP309 and p53R72P polymorphisms and bladder cancer risk in Mongolian populations. According to the results, the homozygous $(\mathrm{G} / \mathrm{G})$ genotype of MDM2 SNP309 is associated with increased risk of bladder cancer in Mongolian populations, but not significantly so. This result is similar to the result of a previous Turkish study, which indicated that the $\mathrm{G} / \mathrm{G}$ genotype was a potential genetic susceptibility factor for bladder cancer $(\mathrm{OR}=2.68$; 95\% $\mathrm{CI}=1.34-5.40)$ (17). Furthermore, 


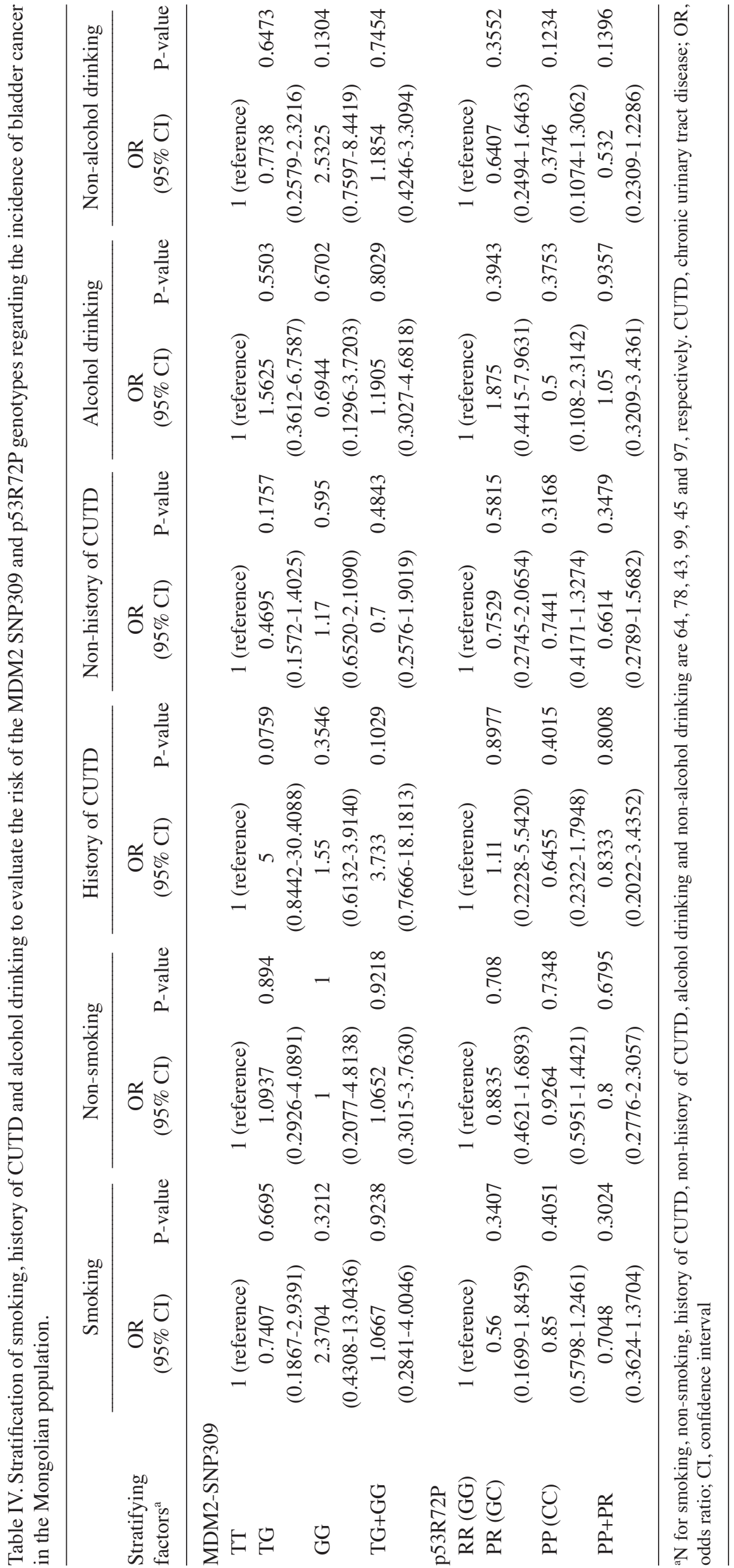


Table V. The risk evaluation of MDM2-SNP309 on bladder cancer stratified for p53 R72P.

\begin{tabular}{|c|c|c|c|c|}
\hline $\mathrm{p} 53 \mathrm{R} 72 \mathrm{P}$ & Cases $(n, \%)$ & Control (n, \%) & OR $(95 \% \mathrm{CI})$ & P-value \\
\hline \multicolumn{5}{|l|}{ RR } \\
\hline \multicolumn{5}{|c|}{ MDM2-SNP309 } \\
\hline $\mathrm{TT}$ & $6,17.1$ & $8,22.2$ & 1 & \\
\hline TG & $16,45.7$ & $21,58.3$ & $1.2925(0.2750-6.0754)$ & 0.7452 \\
\hline GG & $13,37.2$ & $7,19.5$ & $3.3554(0.3914-28.7657)$ & 0.2695 \\
\hline $\mathrm{TG}+\mathrm{GG}$ & $29,82.9$ & $28,77.8$ & $1.8557(0.4455-7.7291)$ & 0.3957 \\
\hline \multicolumn{5}{|l|}{$\mathrm{RP}$} \\
\hline \multicolumn{5}{|c|}{ MDM2-SNP309 } \\
\hline $\mathrm{TT}$ & 6,30 & $3,13.6$ & 1 & \\
\hline $\mathrm{TG}$ & 9,45 & $13,59.1$ & $0.1011(0.0067-1.5284)$ & 0.0982 \\
\hline GG & 5,25 & $6,27.3$ & $0.1289(0.0066-2.5307)$ & 0.1774 \\
\hline $\mathrm{TG}+\mathrm{GG}$ & 14,70 & $19,86.4$ & $0.1611(0.0174-1.4937)$ & 0.2334 \\
\hline \multicolumn{5}{|l|}{ PP } \\
\hline \multicolumn{5}{|c|}{ MDM2-SNP309 } \\
\hline TT & $1,12.5$ & $6,31.6$ & 1 & \\
\hline $\mathrm{TG}$ & $5,62.5$ & $9,47.4$ & $0.3607(0.0177-7.3437)$ & 0.5072 \\
\hline GG & 2,25 & 4,21 & $47.692(0.0015-1512560.1357)$ & 0.4649 \\
\hline $\mathrm{TG}+\mathrm{GG}$ & $7,87.5$ & $13,68.4$ & $3.0848(0.1990-47.8194)$ & 0.4205 \\
\hline
\end{tabular}

Table VI. Comparison of age at diagnosis of bladder cancer in Mongolian patients according to MDM2-SNP309 genotype.

\begin{tabular}{lccc}
\hline MDM2-SNP309 & GG & TG & TT \\
\hline Sample size & 28 & 38 & 18 \\
Median age (years) & 60 & 59 & 50.5 \\
Mean age \pm SD & $52.35 \pm 8.9$ & $53 \pm 13.77$ & $55.46 \pm 10.14$ \\
\hline
\end{tabular}

SD standard deviation.

A

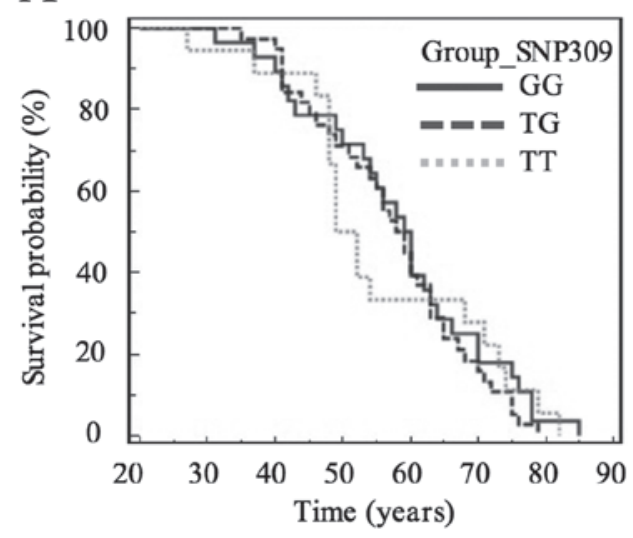

Table VII. Comparison of age at diagnosis bladder cancer in Mongolian patients according to p53R72P genotype.

\begin{tabular}{lccc}
\hline p53R72P & RR & RP & PP \\
\hline Sample size & 45 & 29 & 10 \\
Median age (years) & 58 & 52 & 61 \\
Mean age \pm SD & $53.81 \pm 8.86$ & $51.73 \pm 12.49$ & $54.73 \pm 16.78$
\end{tabular}

$\mathrm{SD}$, standard deviation.

B

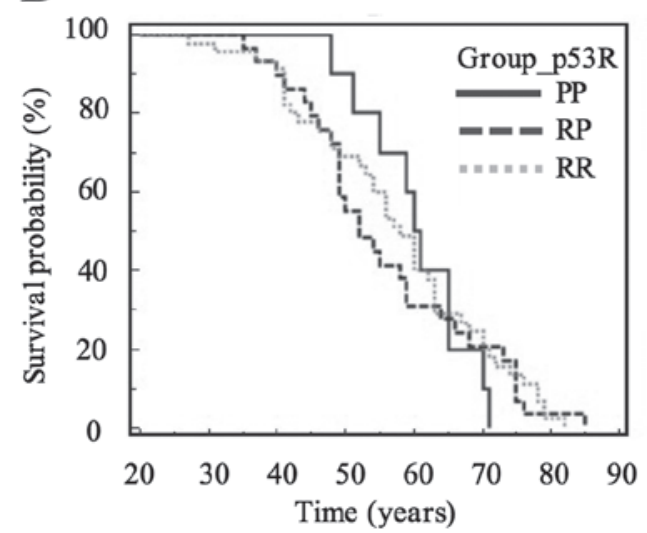

Figure 1. Comparison of age at diagnosis among different genotypes of (A) MDM2-SNP309 and (B) p53R72P. The Y axis is the cumulative case-free survival plotted against age at diagnosis, and the statistical analysis was performed using the log-rank test.

it is partially consistent with previous studies reporting that the G allele of MDM2-SNP309 is associated with the development of an aggressive tumor phenotype but not overall risk of bladder cancer in Caucasian Japanese populations $(16,19)$. 
In the present study, several risk factors for bladder cancer including smoking, drinking alcohol and history of urinary tract infections exhibited significant differences between cases and controls, as determined via structured questionnaires (21). Smoking and history of chronic urinary tract disease increased the risk association of the $\mathrm{G} / \mathrm{G}$ genotype of MDM2-SNP309 with bladder cancer, whereas the T/G genotype of MDM2-SNP309 may increase the risk following stratification by history of urinary tract disease and drinking alcohol, but not smoking.

In the current study, for p53 Arg72Pro genotypes, each genotype individually was not associated with the risk of bladder cancer in Mongolian populations. These results were similar to the results of studies conducted among Japanese and north Indian populations $(19,22)$. Notably, according to a meta-analysis of 15 publications, p53R72P is associated with the risk of bladder cancer in Asian but not Caucasian patients (9). However, the north Indian population was categorized as Caucasian in this previous meta-analysis (11). Furthermore, patients with the $\mathrm{P} / \mathrm{P}$ genotype of $\mathrm{p} 53 \mathrm{R} 72 \mathrm{P}$ increased the risk (OR=3.02; 95\% CI=1.42-6.40) of the development of bladder cancer in Bangladeshi populations (23). Another meta-analysis reported that, in Caucasians, the wild-type $(\mathrm{R} / \mathrm{R})$ genotype of $\mathrm{p} 53 \mathrm{R} 72 \mathrm{P}$ increases the risk $(\mathrm{OR}=1.64 ; 95 \% \mathrm{CI}=1.18-2.28)$, but the heterozygous $(\mathrm{R} / \mathrm{P})$ genotype reduces the risk $(\mathrm{OR}=0.62$; 95\% CI=0.44-0.99) of bladder cancer (24).

In the current study, when the genotypes of p53R72P were stratified by the confounding factors, only the R/P genotype increased the risk of bladder cancer in patients drinking alcohol. Furthermore, the combination of the R/R genotype of p53R72P with the G/G genotype of MDM2-SNP309 was associated with increased risk of bladder cancer in the present study (Table V). It is speculated that the G/G genotype of MDM2-SNP309 may suppress the level of wild-type (R/R) p53 and increase the risk of cancer development accordingly. The present results found no association between these two SNPs and early age onset of bladder cancer. However, the sample size was too small to determine the interaction between these two SNPs.

The current study has several limitations that may have influenced the results. A major potential limitation of the study was the small patient sample size; the study involved 79 controls and 63 patients with bladder cancer who participated fully, although 129 controls and 141 patients were initially enrolled in the research. This may be due to the population density, large geographical area and lack of specialized cancer registry system. However, the number of volunteers in the present study may be standard compared with similar studies in regards to population $(16,17,19,22)$. For Mongolians, lifestyle and diet (primarily red meat and dairy) are not the critical risk factors for bladder cancer development in the present study. Regarding sex, males were 3.5 times more affected by bladder cancer than females in the current study. This result is similar to a previous study in that the incidence, staging and prognosis of bladder cancer was associated with sex (25).

In conclusion, the current data suggest no significant association between MDM2-SNP309 and p53R72P and the risk of bladder cancer in Mongolian populations. Patients who smoke or have urinary tract disease have an enhanced bladder cancer risk effect associated with MDM2-SNP309 but not p53R72P. The present study failed to demonstrate any association between early age at onset of MDM2-SNP309 and p53R72P and the development of bladder cancer. As these statistical results were based on small sample sizes of cases and controls, enlargement of the volunteer pool may be important to further elucidate the effect of MDM-SNP309 and p53R72P on the risk of Mongolian bladder cancer.

\section{Acknowledgements}

The present study was supported by The National Science Council (now Minister of Science and Technology), Taiwan (NSC101-2923-B-010-001-MOST 105-2628-B-010-013-MY3) and The Mongolian Foundation for Science and Technology (NSC-MECS2012004). The authors would also like to thank Miss Odgerel, Miss B. Chuluuntsetseg, Miss D. Odgerel, Miss Chun-Yuan Chang and Miss Hsian-Wen Lins' for technical support.

\section{References}

1. Ploeg M, Aben KK and Kiemeney LA: The present and future burden of urinary bladder cancer in the world. World J Urol 27: 289-293, 2009.

2. Sandagdorj T, Sanjaajamts E, Tudev U, Oyunchimeg D, Ochir C and Roder D: Cancer incidence and mortality in Mongolianational registry data. Asian Pac J Cancer Prev 11: 1509-1514, 2010.

3. Bolortuyaa B, Bayarmaa E and Galtsog L: Bladder cancer is diagnosed by pathology. Mongolian Med Sci 2: 12-15, 2010.

4. La Vecchia $\mathrm{C}$ and Airoldi L: Human bladder cancer: Epidemiological, pathological and mechanistic aspects. IARC Sci Publ: 139-157, 1999.

5. Burger M, Catto JW, Dalbagni G, Grossman HB, Herr H, Karakiewicz P, Kassouf W, Kiemeney LA, La Vecchia C, Shariat S and Lotan Y: Epidemiology and risk factors of urothelial bladder cancer. Eur Urol 63: 234-241, 2013.

6. Bond GL and Levine AJ: A single nucleotide polymorphism in the p53 pathway interacts with gender, environmental stresses and tumor genetics to influence cancer in humans. Oncogene 26: 1317-1323, 2007.

7. Hollstein M, Sidransky D, Vogelstein B and Harris CC: p53 mutations in human cancers. Science 253: 49-53, 1991.

8. Hrstka R, Coates PJ and Vojtesek B: Polymorphisms in p53 and the p53 pathway: Roles in cancer susceptibility and response to treatment. J Cell Mol Med 13: 440-453, 2009.

9. Pietsch EC, Humbey O and Murphy ME: Polymorphisms in the p53 pathway. Oncogene 25: 1602-1611, 2006.

10. Thomas M, Kalita A, Labrecque S, Pim D, Banks L and Matlashewski G: Two polymorphic variants of wild-type p53 differ biochemically and biologically. Mol Cell Biol 19: 1092-1100, 1999.

11. Xu T, Xu ZC, Zou Q, Yu B and Huang XE: P53 Arg72Pro polymorphism and bladder cancer risk-meta-analysis evidence for a link in Asians but not Caucasians. Asian Pac J Cancer Prev 13: 2349-2354, 2012.

12. Yang Z, Nie S, Zhu H, Wu X, Jia S, Luo Y and Tang W: Association of p53 Arg72Pro polymorphism with bladder cancer: A meta-analysis. Gene 512: 408-413, 2013.

13. Bond GL, Hu W, Bond EE, Robins H, Lutzker SG, Arva NC, Bargonetti J, Bartel F, Taubert H, Wuerl P, et al: A single nucleotide polymorphism in the MDM2 promoter attenuates the p53 tumor suppressor pathway and accelerates tumor formation in humans. Cell 119: 591-602, 2004.

14. Freedman DA and Levine AJ: Regulation of the p53 protein by the MDM2 oncoprotein-thirty-eighth G.H.A. Clowes Memorial Award Lecture. Cancer Res 59: 1-7, 1999.

15. Knappskog S and Lønning PE: Effects of the MDM2 promoter SNP285 and SNP309 on Sp1 transcription factor binding and cancer risk. Transcription 2: 207-210, 2011.

16. Hitzenbichler F, Stoehr CG, Rogenhofer M, Wieland WF, Ruemmele P, Hartmann A and Stoehr R: Mdm2 SNP309 G-variant is associated with invasive growth of human urinary bladder cancer. Pathobiology 81: 53-59, 2014. 
17. Onat OE, Tez M, Ozçelik T and Törüner GA: MDM2 T309G polymorphism is associated with bladder cancer. Anticancer Res 26: 3473-3475, 2006

18. Sanchez-Carbayo M, Socci ND, Kirchoff T, Erill N, Offit K, Bochner BH and Cordon-Cardo C: A polymorphism in HDM2 (SNP309) associates with early onset in superficial tumors, TP53 mutations, and poor outcome in invasive bladder cancer. Clin Cancer Res 13: 3215-3220, 2007.

19. Horikawa Y, Nadaoka J, Saito M, Kumazawa T, Inoue T, Yuasa T, Tsuchiya N, Nishiyama H, Ogawa O and Habuchi T: Clinical implications of the MDM2 SNP309 and p53 Arg72Pro polymorphisms in transitional cell carcinoma of the bladder. Oncol Rep 20: 49-55, 2008

20. Leu JD, Wang CY, Tsai HY, Lin IF, Chen RC and Lee YJ: Involvement of p53 R72P polymorphism in the association of MDM2-SNP309 with breast cancer. Oncol Rep 25: 1755-1763, 2011.

21. Janković S and Radosavljević V: Risk factors for bladder cancer. Tumori 93: 4-12, 2007.

22. Srivastava P, Jaiswal PK, Singh V and Mittal RD: Role of p53 gene polymorphism and bladder cancer predisposition in northern India. Cancer Biomark 8: 21-28, 2010-2011.
23. Hosen MB, Salam MA, Islam MF, Hossain A, Hawlader MZ and Kabir Y: Association of TP53 gene polymorphisms with susceptibility of bladder cancer in Bangladeshi population. Tumour Biol 36: 6369-6374, 2015.

24. Li DB, Wei X, Jiang LH, Wang Y and Xu F: Meta-analysis of epidemiological studies of association of P53 codon 72 polymorphism with bladder cancer. Genet Mol Res 9: 1599-1605, 2010.

25. Fajkovic H, Halpern JA, Cha EK, Bahadori A, Chromecki TF, Karakiewicz PI, Breinl E, Merseburger AS and Shariat SF: Impact of gender on bladder cancer incidence, staging, and prognosis. World J Urol 29: 457-463, 2011. 